\title{
BEACH EROSION ON GOLDEN BEACH IN SOUTH TAIWAN
}

Chun-Hung Pao, Ocean Affairs Council, Taiwan, chpao@oac.gov.tw Takaaki Uda, Public Works Research Center, uda@pwrc.or.jp

Yu-Hsiang Lin, Sixth River Management Office, WRA, MOEA, Taiwan, wra06028@wra06.gov.tw

Jia-Lin (Julie) Chen, National Cheng Kung University, jialinchenpsu@gmail.com

\section{INTRODUCTION}

Golden Beach in Taiwan is a sandy beach attracting many beachgoers because of its wide sandy beach and beautiful sunset (Fig. 1). In recent years, this beach has been eroded. The cause of the beach erosion is considered to be due to the wave-sheltering effect of the Anping Harbor breakwaters constructed $4 \mathrm{~km}$ north of the beach. Now the restoration of sandy beach is underway by the construction of groins as well as beach nourishment using sand procured from the downcoast deposition area. This study aims to investigate the cause of the beach erosion of this beach to work out the effective measures against beach erosion.

\section{CONTENTS}

The construction of the Anping Harbor breakwaters started in 1999 and completed by 2004. In 1985, a wide sandy beach extended on Golden Beach. After the construction of Anping Harbor, the shoreline on this beach retreated by 120-160 m due to the erosion. In this study, the damage of Golden Beach and shoreline changes were investigated using site photographs and satellite images as well as the analysis of the bathymetric survey data. The shoreline on Golden Beach has retreated in recent years, and the seawall was severely damaged. On June 6, 2002 before the erosion, a wide foreshore extended, and a vegetation zone extended in front of the seawall, implying that the backshore was stable against waves, as shown in Fig. 2. The seawall, however, had been severely damaged by January 26, 2011, and the walkway fell down owing to the successive erosion, and concrete blocks were placed in front of the damaged seawall (Fig. 3).

\section{ANALYSIS OF BATHYMETRIC SURVEY DATA}

Figure 4 shows the shoreline changes between 1985 and 2014 in the study area. The shoreline gradually advanced in the area between $X=2.8 \mathrm{~km}$ and Anping Harbor between 1985 and 2014. In contrast, the shoreline between the Erren River mouth and $X=2.8 \mathrm{~km}$ retreated with a maximum shoreline recession of $140 \mathrm{~m}$. A wide foreshore was formed south of the Anping 
Harbor breakwater, and a lowland with an elevation of $2.2 \mathrm{~m}$ above MSL were formed because of succesive sand supply from the south. The bathymetry in the study area is shown in Fig. 5, together with four transects along which profile changes were compared between November 2010 and October 2015. Figure 5 clearly shows that northward longshore sand transport was entirely blocked by the south breakwater of Anping Harbor, and a large amount of sand was deposited. Figure 6 shows the bathymetry in October 2015 of the same area as that shown in Fig. 5. Although the overall features of the bathymetry do not change in the five years, many groins were constructed between the Erren River mouth and Golden Beach as a measure against beach erosion, with 13 shorter groins near the river mouth and 8 longer groins in front of Golden Beach. Despite the construction of these groins, wide beach, as shown in Fig. 2, has not been restored. Figure 7 shows the bathymetric changes between 2002 and 2015. A large amount of sand was deposited north of $X=2.8 \mathrm{~km}$, whereas severe erosion occurred in the south part, particularly offshore the Erren River mouth. Offshore of the deposition zone south of Anping Harbor, a slender erosion zone with depths ranging -3 or $-5 \mathrm{~m}$ extends northward until the attachement to the south breakwater. Although significant profile changes can be seen in offshore area, the profile changes almost converge $-6 \mathrm{~m}$, implying that the depth of closure $h_{\mathrm{c}}$ is $-6 \mathrm{~m}$. When longshore sand transport is blocked by a structure, sand is deposited upcoast of the structure, resulting in shoreline advance, whereas on the downcoast, the shoreline retreats and a concave profile is formed owing to the successive erosion. In this case, the change in shoreline position $\Delta y$ and the change in the cross-sectional area $\Delta A$ can be determined from the profile changes. If we consider the correlation between $\Delta A$ and $\Delta y$, a linear relationship is generally obtained between them, and this regression coefficient between them gives the characteristic height of beach changes $h$ which can be used as a constant for transforming the change in the foreshore area of the beach into the change in the volume of sand of the beach (Uda, 2017). In the present case, we obtained the relationship of $\Delta A=9.2 \Delta y$, and $h$ becomes $9.2 \mathrm{~m}$. This value is close to the sum of the berm height $h_{\mathrm{R}}$ of $2.2 \mathrm{~m}$ and the depth of closure $h_{\mathrm{c}}$ of $6 \mathrm{~m}$. Furthermore, the increase in foreshore area south of Anping Harbor is given by $2.2 \times 10^{5} \mathrm{~m}^{2}$ from the shoreline change. When multiplying this value by $h=9.2 \mathrm{~m}$, the entire volume of sand deposited upcoast was calculated to be $2.0 \times 10^{6} \mathrm{~m}^{3}$. Since the construction of the Anping Harbor breakwaters began in 1999, 16 years have passed since then, and the annual rate of the deposition of sand has become $1.25 \times 10^{5} \mathrm{~m}^{3} / \mathrm{yr}$, which is equal to longshore sand supply from the south coast. Thus, it was concluded that the beach erosin and accretion were triggered by this longshore sand transport.

\section{CONCLUSIONS}


At present, the length of the south breakwater measured off the coast is $1.9 \mathrm{~km}$ and the point depth is $13 \mathrm{~m}$ below MSL, which is much greater than the depth of closure $h_{c}$ of $6 \mathrm{~m}$ below MSL, and longshore sand transport was completely blocked by the port breakwaters. Moreover, the wave direction at Golden Beach seasonally varies from the SW to the NW, so that the wave direction alternately changes in this area, implying that sand transported on the south side of Anping Harbor during the summer season could not easily escape from the wave-shelter zone of Anping Harbor in winter, causing marked sand deposition in the area adjacent to the port. As a measure against beach erosion in this area, it is considered that groins with a point depth comparable to the depth of closure should be extended seaward, together with beach nourishment using sand deposited immediately south of Anping Harbor. Although some part of the sand is gradually transported northward, because the point depth of the groin is smaller than the depth of closure, sand deposited immediately south of the port could be reused to create the dynamic stability of the beach by the recycle use of sand.

\section{REFERENCES}

Uda, T. (2017): Japan's Beach Erosion - Reality and Future Measures, $2^{\text {nd }}$ ed., World Scientific, p. 530.

Uda,T., Tsai, Tsung-Hsien, Lin, Yu-Hsiang and Pao, Chun-Hung Pao (2016): Beach erosion on Golden Beach in south Taiwan, J. JSCE, B3 (Civil Eng. in the Ocean), Vol. 72, No. 2, pp. I_79-I_84. 


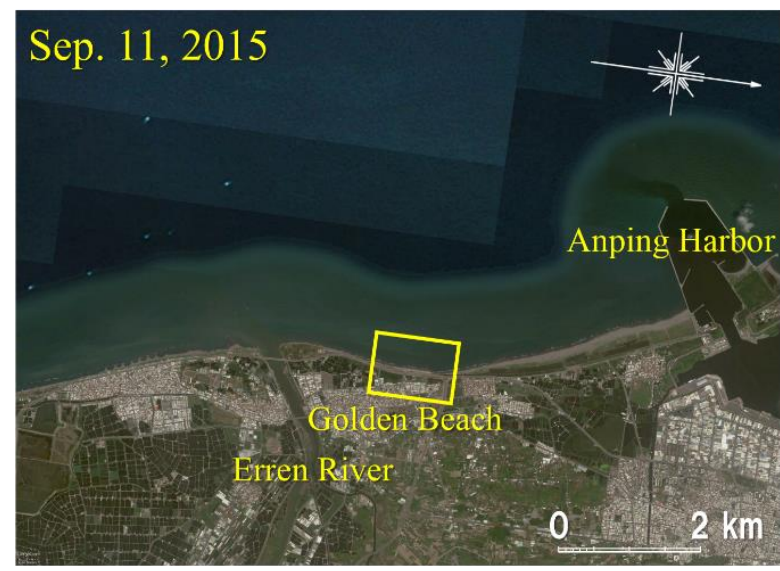

Figure 1. Location of Golden Beach and Anping Harbor.

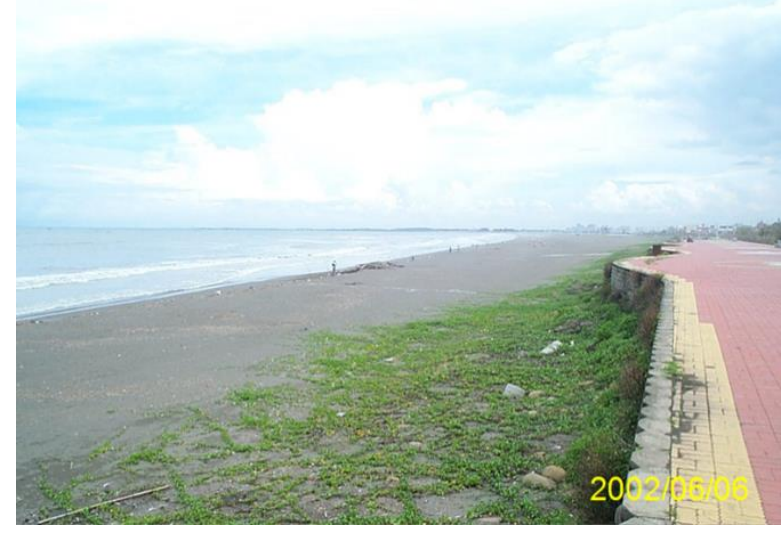

Figure 2. Photograph of Golden Beach taken on June 6, 2002 .

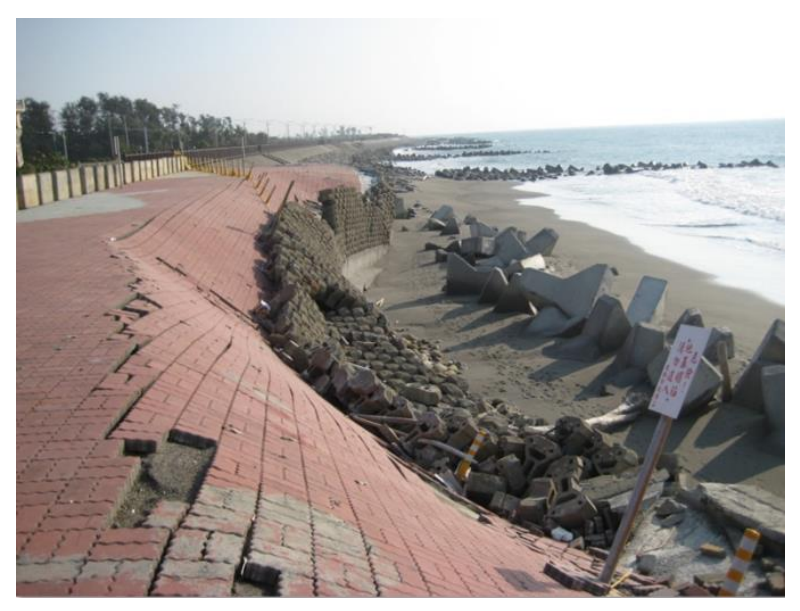

Figure 3. Damaged seawall on Golden Beach on January 26, 2011, looking south.

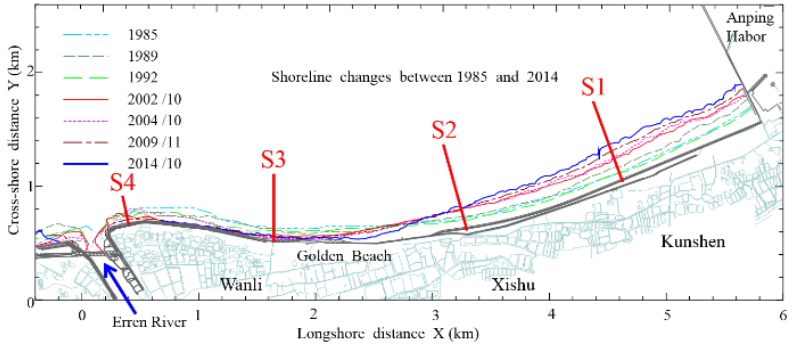

Figure 4. Shoreline changes between 1985 and 2014.

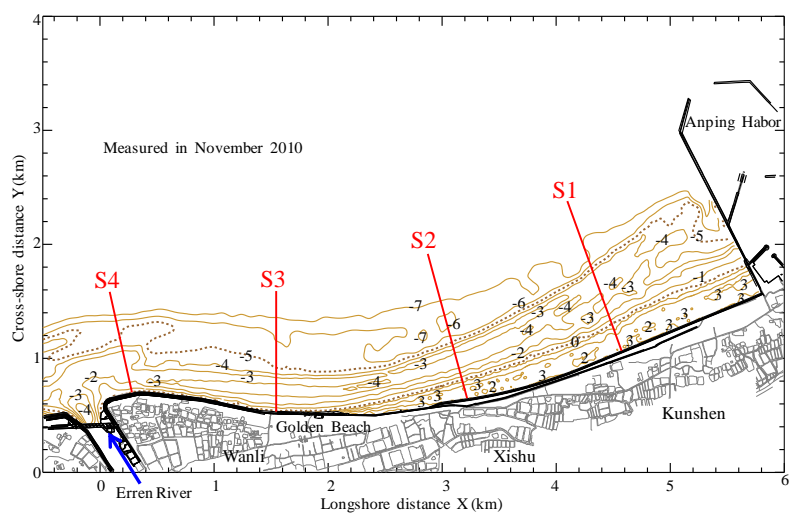

Figure 5. Bathymetry of study area between the Erren

River mouth and Anping Harbor (November 2010).

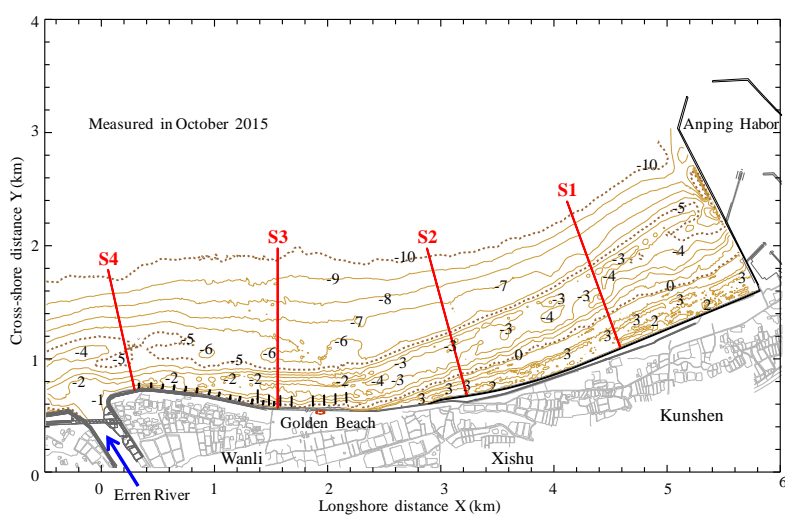

Figure 6. Bathymetry of study area between the Erren River mouth and Anping Harbor (October 2015).

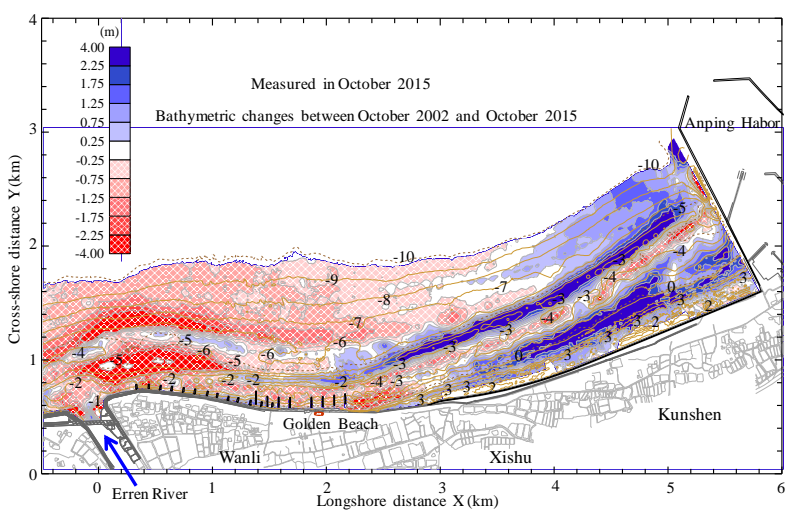

Figure 7. Bathymetric changes between 2002 and 2015. 